\title{
Oblique Intrathecal Injection in Lumbar Spine Surgery: A Technical Note
}

\author{
Gordon A.E. Jewett, Daniel Yavin, Perry Dhaliwal, Tara Whittaker, \\ JoyAnne Krupa, Stephan Du Plessis
}

\begin{abstract}
Objectives: Intrathecal morphine (ITM) is an efficacious method of providing postoperative analgesia and reducing pain associated complications. Despite adoption in many surgical fields, ITM has yet to become a standard of care in lumbar spine surgery. Spine surgeons' reticence to make use of the technique may in part be attributed to concerns of precipitating a cerebrospinal fluid (CSF) leak. Methods: Herein we describe a method for oblique intrathecal injection during lumbar spine surgery to minimize risk of CSF leak. The dural sac is penetrated obliquely at a $30^{\circ}$ angle to offset dural and arachnoid puncture sites. Oblique injection in instances of limited dural exposure is made possible by introducing a $60^{\circ}$ bend to a standard 30-gauge needle. Results: The technique was applied for injection of ITM or placebo in 104 cases of lumbar surgery in the setting of a randomized controlled trial. Injection was not performed in two cases $(2 / 104,1.9 \%)$ following preinjection dural tear. In the remaining 102 cases no instances of postoperative CSF leakage attributable to oblique intrathecal injection occurred. Three cases $(3 / 102,2.9 \%)$ of transient CSF leakage were observed immediately following intrathecal injection with no associated sequelae or requirement for postsurgical intervention. In two cases, the observed leak was repaired by sealing with fibrin glue, whereas in a single case the leak was self-limited requiring no intervention. Conclusions: Oblique dural puncture was not associated with increased incidence of postoperative CSF leakage. This safe and reliable method of delivery of ITM should therefore be routinely considered in lumbar spine surgery.
\end{abstract}

RÉSUMÉ: Note technique à propos de l'injection intrathécale oblique lors d'une chirurgie à la colonne lombaire. Objectifs : L'injection intrathécale de morphine (ITM) est un moyen efficace d'analgésie postopératoire et aide à diminuer la douleur associée aux complications. Malgré son adoption dans plusieurs domaines chirurgicaux, l'ITM n'est pas encore devenue la norme en chirurgie de la colonne lombaire. La réticence des chirurgiens qui pratiquent ce type de chirurgie à utiliser cette technique pourrait être due en partie à la crainte de provoquer une fuite de liquide céphalorachidien (LCR). Méthodologie : Nous décrions une méthode d'injection intrathécale oblique pendant la chirurgie de la colonne lombaire pour minimiser le risque de fuite du LCR. Le sac dural est pénétré obliquement à un angle de $30^{\circ}$ afin de décaler les sites de ponction au niveau dural et arachnoïdien. Une injection oblique dans le cas d'un accès dural limité est rendue possible en courbant une aiguille de calibre 30 à $60^{\circ}$. Résultats : La technique a été utilisée pour ITM ou injection de placebo chez 104 patients lors d'une chirurgie à la colonne lombaire dans le contexte d'une étude randomisée contrôlée. L'injection n'a pas été effectuée chez 2 sujets $(2 / 104,1,9 \%)$ à cause d'une déchirure durale survenue préalablement. Chez les 102 autres sujets, aucune fuite de LCR attribuable à l'injection intrathécale oblique n'est survenue. Une fuite transitoire de LCR a été observée immédiatement après l'injection intrathécale chez 3 sujets (3/ 102, 2,9\%), sans séquelle associée ou nécessité de réintervention après la chirurgie. Chez 2 sujets, la fuite observée a été réparée en la scellant avec de la colle de fibrine alors que chez l'autre sujet aucune intervention n'a été nécessaire. Conclusions : Une ponction durale oblique n'a pas été associée à une incidence accrue de fuite du LCR en période postopératoire. Cette méthode sûre et fiable d'ITM devrait donc être envisagée de routine dans la chirurgie de la colonne lombaire.

Keywords: cerebrospinal fluid leak, intrathecal injection intrathecal morphine, lumbar spine surgery, operative technique, postoperative analgesia

doi:10.1017/cjn.2017.45

Can J Neurol Sci. 2017; 44: 514-517

Intrathecal morphine (ITM) has been adopted as an adjunct to traditional postoperative analgesia in the fields of obstetric, cardiac, urologic, and orthopedic surgery. ${ }^{1-4}$ Through a single intrathecal injection of morphine, patients benefit from prolonged postoperative analgesia without the need for indwelling catheters or continuous infusions. The resulting improvement in pain management significantly reduces the need for intravenous opioid analgesia, improves time to mobilization, and shortens length of hospital stay. ${ }^{5-7}$ Although routine use of ITM has long been implemented in many surgical specialties, it has yet to become

From the Departments of Clinical Neurosciences (GAEJ, DY, TW, SDP) and Community Health Sciences (DY), University of Calgary, Calgary, Alberta, Canada; Division of Neurosurgery (PD), Department of Surgery, University of Manitoba, Winnipeg, Manitoba, Canada; Faculty of Medicine (JK), University of British Columbia, Vancouver, British Columbia, Canada

Received August 18, 2016. Final Revisions Submitted January 28, 2017. Date of Acceptance March 5, 2017.

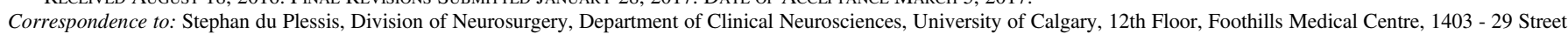
NW, Calgary, AB T2N 2T9, Canada. Email: Stephan.DuPlessis@ albertahealthservices.ca 
standard operative care in the setting of lumbar spine surgery despite multiple reports of the safety and efficacy. ${ }^{7-12}$

Open lumbar spine surgery provides an opportunity for intrathecal injection under direct visualization of the exposed thecal sac before wound closure with technical ease. A theoretical concern of this procedure particularly relevant to spine surgeons is the risk of an iatrogenic cerebrospinal fluid (CSF) leak with dural puncture. Limited exposure of the thecal sac and the depth of the incision often necessitate the administration of ITM through a needle held nearly perpendicular to the dural sac. As a result, punctures through the dura and arachnoid occur along a contiguous plane, potentially creating a channel through which CSF can flow. Iatrogenic CSF leaks following puncture of the dural sac with the needle held perpendicular to the dural surface have been reported. ${ }^{11}$

Herein we describe a technique for oblique injection into the dural sac that is feasible in cases where dural sac exposure is limited. Oblique injection has the benefit of offsetting punctures in the dura and arachnoid to minimize CSF leak risk. This technique can be performed easily and quickly with standard surgical equipment. Through use of this technique, patients undergoing spine surgery may benefit from ITM while limiting the theoretical risk of iatrogenic CSF leak.

\section{INJECTION TECHNIQUE}

Oblique injection can be accomplished with the use of equipment readily at hand in the operating theatre and without significantly prolonging operative time. A standard 30-gauge needle is used to mitigate trauma to the dural sac while accommodating a $60^{\circ}$ bend without compromising the lumen. The bend procedure is performed using a 6-inch Crile Wood Needle Holder. The 30-gauge needle is grasped just distal of the syringe with the needle holder and a moment force is applied toward the direction of the open needle bevel (Figure 1). The needle is bent to a $60^{\circ}$ angle (Figure 2).

During injection, the syringe is held perpendicular to the surface of the dural sac. The $60^{\circ}$ bend results in the needle approaching the dural surface at a $30^{\circ}$ angle. This angle can be reduced or increased as desired to accommodate the depth of the incision or extent of exposure. The needle is passed into the intrathecal space and the injection is performed under direct visualization. The intrathecal injection is performed at the end of the procedure when the dural sac is maximally exposed, and immediately before closure.

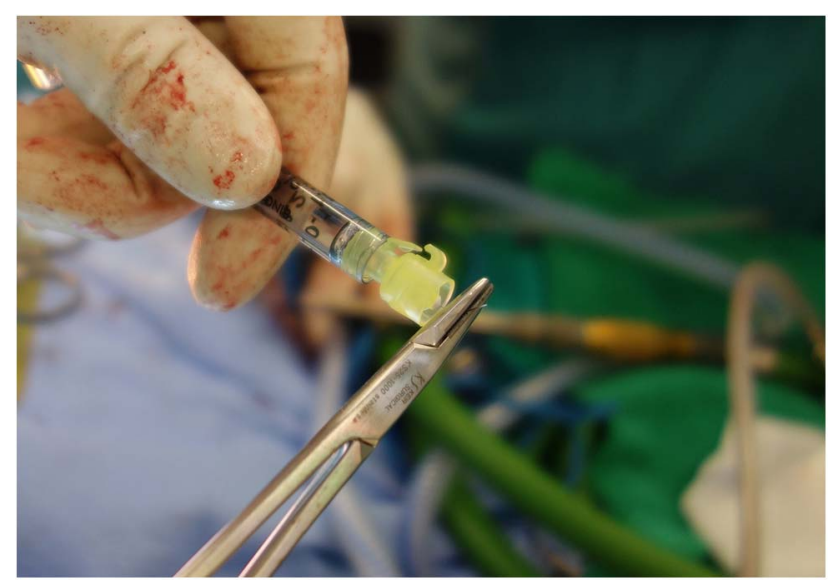

Figure 1: The needle is prepared for injection by applying a $60^{\circ}$ bend towards the open side of the bevel.

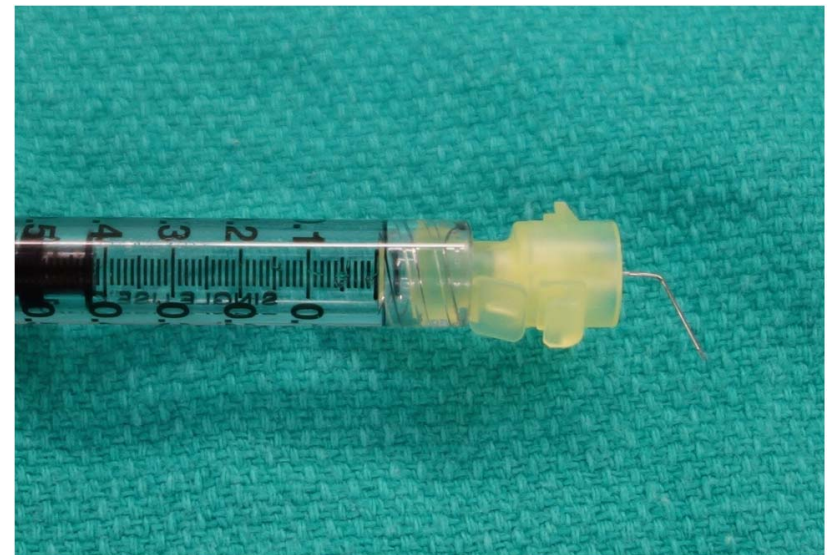

Figure 2: A prepared 30-gauge needle with $60^{\circ}$ bend is ready for injection. The lumen is not compromised by the bend procedure.

\section{METHODS}

Participating spinal surgeons were provided with brief instructions outlining the injection technique. A total of $0.4 \mathrm{ml}$ of fluid was injected with the oblique intrathecal injection technique during open lumbar spine surgery when the dura was fully exposed before closure. According to the study arm of the randomized controlled trial to which patients were assigned, they were administered either $200 \mathrm{mcg}$ of $500 \mathrm{mcg} / \mathrm{ml}$ Epimorph (preservative-free morphine sulphate, total volume $0.4 \mathrm{ml}$ ) or $0.4 \mathrm{ml}$ of saline placebo. Assessment of iatrogenic leaks was made through visual inspection of the injection site immediately following injection. Valsalva maneuvers were used only at the discretion of the treating surgeon and were not required by the study protocol. Additionally, patients were monitored postoperatively for signs and symptoms of CSF leak and other complications by a research nurse during a follow-up period lasting the duration of their postoperative stay. Surgical site drains were placed at the discretion of the treating surgeon according to individual practice; they were placed to active suction in the immediate postoperative period in less than one-quarter of patients. Adherence and complications were collected prospectively in the setting of a randomized controlled trial investigating use of ITM.

\section{Results}

The oblique injection technique was applied to 104 cases of elective open posterior instrumented fusion between L2 and the sacrum at our institution. Patient, surgical, and follow-up characteristics are shown in Table 1 . In two cases $(2 / 104,1.9 \%)$, nonadherence followed preinjection dural tear. In the 102 cases in which oblique injection was performed, there were no instances of postoperative CSF leakage. Three cases (3/102, $2.9 \%$ ) of transient CSF leakage were observed intraoperatively immediately following intrathecal injection, with no associated sequelae or requirement for postsurgical intervention. In two cases, the observed leak was repaired with fibrin (TISSEEL, Baxter) glue, whereas in a single case the leak was selflimited. There were no cases of postsurgical intervention or complication related to CSF leak during postoperative inpatient follow-up lasting a median of 96 hours with standard deviation of 2 hours. 


\section{Table 1: Patient, surgical, and follow-up characteristics}

\begin{tabular}{l|c}
\hline Characteristic & Number \\
\hline Demographics & $\mathrm{N}=104$ \\
\hline Age (years) & $69.9 \pm 12.5$ \\
\hline Male, no. (\%) & $64(62)$ \\
\hline Primary diagnosis, no. (\%) & $5(5)$ \\
\hline Spinal stenosis* & $95(91)$ \\
\hline Spondylolisthesis & $3(3)$ \\
\hline Disc herniation ${ }^{\dagger}$ & $1(1)$ \\
\hline Spondylosis & $13(13)$ \\
\hline Previous lumbar decompression, no. (\%) & \\
\hline Surgical characteristics, no. (\%) & $104(100)$ \\
\hline Posterior midline access & $104(100)$ \\
\hline Instrumented fusion & \\
\hline Levels fused & $72(69)$ \\
\hline 1 & $25(24)$ \\
\hline 2 & $5(5)$ \\
\hline 3 & $2(2)$ \\
\hline 4 & $96 \pm 2.0$ \\
\hline Length of postoperative inpatient follow-up, hours & \\
\hline
\end{tabular}

Plus-minus values are medians \pm standard deviation.

*In the absence of spondylolisthesis.

${ }^{\dagger}$ In the absence of the spondylolisthesis or spinal stenosis.

${ }^{\ddagger}$ In the absence of spondylolisthesis, spinal stenosis, or disc herniation.

\section{Discussion}

The potential benefits of offsetting puncture sites in adjacent tissue layers has been established in other medical procedures such as paracentesis, where angular insertion and Z-tract insertion techniques are used to offset epidermal and peritoneal punctures and reduce risk of ascitic fluid leak. ${ }^{13}$

An injection angle of $30^{\circ}$ relative to the dural surface results in offset between punctures of the dura and arachnoid. Mean lumbar dura thickness ranges from 0.3 to $0.4 \mathrm{~mm}$, whereas arachnoid membrane thickness ranges from 35 to $40 \mu \mathrm{m} \cdot{ }^{14-16}$ Injecting through a $0.35-\mathrm{mm}$ thick dura at a $30^{\circ}$ angle results in an estimated $0.61 \mathrm{~mm}$ offset between entry into the dura and puncture of the arachnoid (Figure 3); this almost entirely eliminates overlap between the dura and arachnoid penetration sites if a 30 -gauge needle $(0.31 \mathrm{~mm}$ outer diameter) is used. Figure 3 illustrates the importance of both needle gauge and injection angle in creating offset between punctures in adjacent layers. Additionally, the oblique needle trajectory is near perpendicular to the expansile CSF pressure within the dural sac, which potentially seals the injection tract.

In our study, this technique was used for open spine surgery only with a traditional posterior midline incision and instrumented fusion. ITM has been used extensively via transcutaneous injection, which approximates oblique injection out of necessity to pass the needle between spinous processes. ${ }^{1-4}$ This technique could theoretically be applied to minimally invasive surgery with a tubular retractor by using a longer needle with a short distal bent segment; however, we did not specifically assess the applicability or limitations of adapting this technique for minimally invasive surgery.

Although complications with this technique appear to be uncommon, they may be serious and their long-term effects uncertain. The rate of nerve root injury observed in our surgical cases was $3 \%$, which was not meaningfully different from previously published complication rates. ${ }^{17,18}$ Neural injury is a theoretical risk of intrathecal injection; however, nerve rootlets and the needle tip can be visualized through the dura. With care, nerve rootlet injury can be avoided; treating surgeons did not observe direct neural injury as a result of intrathecal injection in our study group.

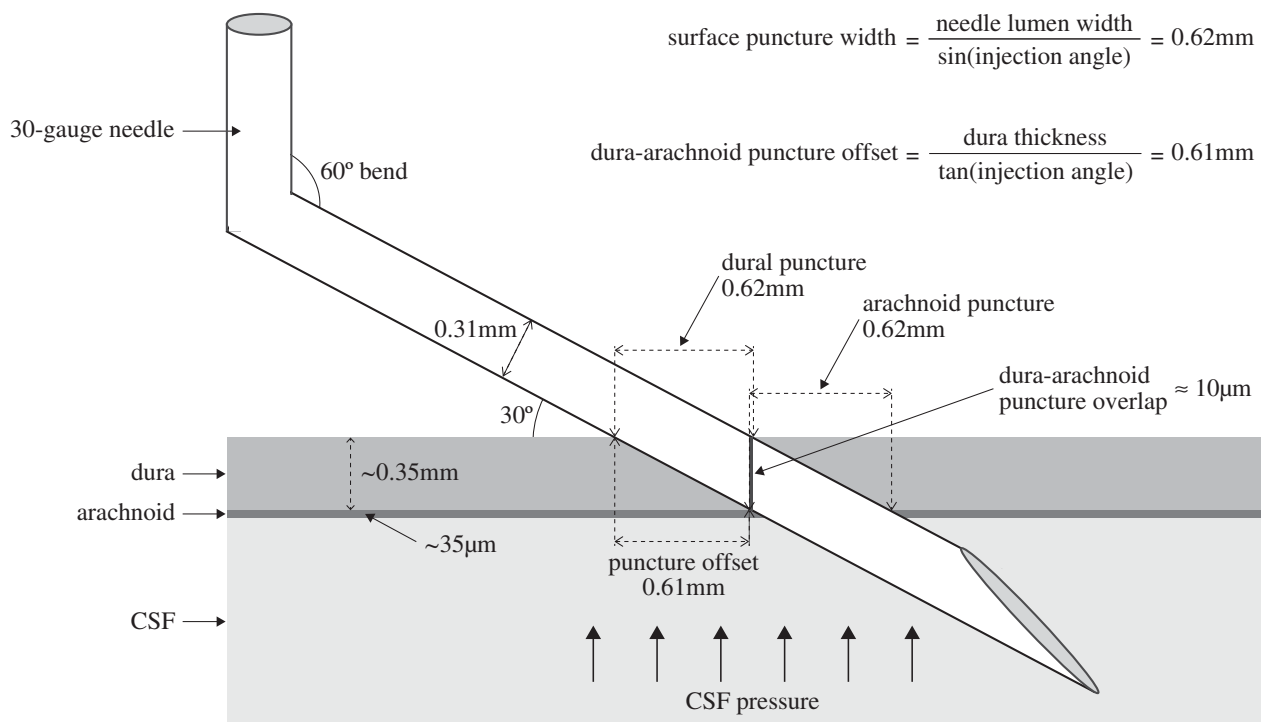

Figure 3: Injecting at $30^{\circ}$ from the dural surface creates nearly complete offset between punctures of the dura and arachnoid. With an estimated dura thickness of $0.35 \mathrm{~mm}$, a 30-gauge needle $(0.31 \mathrm{~mm}$ outer diameter) creates an initial puncture approximately $0.62 \mathrm{~mm}$ wide. The leading lumen wall of the needle travels approximately $0.61 \mathrm{~mm}$ horizontally between initial dura penetration and arachnoid penetration. The result is a theoretical overlap of only $10 \mu \mathrm{m}$ between dura and arachnoid puncture sites. CSF pressure within the dural sac may contribute to sealing the injection lumen. 
Postoperative meningitis and arachnoiditis were not observed in our study, but are potential complications of any disruption of the meninges. CSF fistula is theoretically potentiated in the setting of CSF leak by use of surgical site drains on active suction. These were placed in less than one-quarter of our patients without observed complication. No dural tears were attributed to intrathecal injection, although this is theoretically possible. It may be reasonable to avoid intrathecal injection in patients with particularly fragile meninges where dural injury may be more likely. Intrathecal catheters for long-term opioid use are associated with formation of granulomas. ${ }^{19} \mathrm{We}$ are not aware of any complications of this nature resulting from a single injection.

\section{Conclusions}

Despite demonstrated safety and efficacy of ITM in lumbar spine surgery, the risk of precipitating a CSF leak remains as a barrier to widespread adoption of this analgesic technique. ${ }^{8-12}$ Introducing a bend to the needle facilitates an oblique approach to intrathecal injection, even in a limited working space. Oblique injection when the dural sac is exposed intraoperatively ensures that punctures of the dura and arachnoid are offset. This theoretically improves puncture sealing and eliminates the direct path for CSF leak that exists when injecting perpendicularly. Oblique intrathecal injection is not associated with increased incidence of postoperative CSF leakage and is therefore a simple and effective way of administering ITM. This technique could be applied to administration of other intrathecal substrates in the future.

\section{Disclosures}

The authors do not have anything to disclose.

\section{REFERENCES}

1. Abboud TK, Dror A, Mosaad P, et al. Mini-dose intrathecal morphine for the relief of post-cesarean section pain: safety, efficacy, and ventilatory responses to carbon dioxide. Anesth Analg. 1988;67:137-43.

2. Fitzpatrick GJ, Moriarty DC. Intrathecal morphine in the management of pain following cardiac surgery. A comparison with morphine i.v. Br J Anaesth. 1988;60:639-44.

3. Kalso E. Effects of intrathecal morphine, injected with bupivacaine, on pain after orthopaedic surgery. Br J Anaesth. 1983;55:415-22.

4. Kirson LE, Goldman JM, Slover RB. Low-dose intrathecal morphine for postoperative pain control in patients undergoing transurethral resection of the prostate. Anesthesiology. 1989;71:192-5.
5. Rathmell JP, Lair TR, Nauman B. The role of intrathecal drugs in the treatment of acute pain. Anesth Analg. 2005;101(5 Suppl): S30-43.

6. Rawal N, Sjostrand U, Christoffersson E, Dahlstrom B, Arvill A, Rydman H. Comparison of intramuscular and epidural morphine for postoperative analgesia in the grossly obese: influence on postoperative ambulation and pulmonary function. Anesth Analg. 1984;63:583-92.

7. Ziegeler S FE, Bauer C, Mencke T, Müller BI, Soltesz S, Silomon M. Therapeutic effect of intrathecal morphine after posterior lumbar interbody fusion surgery. Spine. 2008;33:2379-86.

8. France JC, Jorgenson SS, Lowe TG, Dwyer AP. The use of intrathecal morphine for analgesia after posterolateral lumbar fusion: a prospective, double-blind, randomized study. Spine. 1997;22:2272-7.

9. Johnson RG, Miller M, Murphy M. Intraspinal narcotic analgesia. A comparison of two methods of postoperative pain relief. Spine. 1989;14:363-6

10. Techanivate A, Kiatgungwanglia P, Yingsakmongkol W. Spinal morphine for post-operative analgesia after lumbar laminectomy with fusion. J Med Assoc Thailand. 2003;86:262-9.

11. Ziegeler S, Fritsch E, Bauer C, et al. Therapeutic effect of intrathecal morphine after posterior lumbar interbody fusion surgery: a prospective, double-blind, randomized study. Spine. 2008; 33:2379-86.

12. Yorukoglu D, Ates Y, Temiz H, Yamali H, Kecik Y. Comparison of low-dose intrathecal and epidural morphine and bupivacaine infiltration for postoperative pain control after surgery for lumbar disc disease. J Neurosurg Anesthesiol. 2005;17:129-33.

13. Thomsen TW, Shaffer RW, White B, Setnik GS. Videos in clinical medicine. Paracentesis. N Engl J Med. 2006;355:e21.

14. Hong JY, Suh SW, Park SY, et al. Analysis of dural sac thickness in human spine-cadaver study with confocal infrared laser microscope. Spine. 2011;11:1121-7.

15. Reina MA, Prats-Galino A, Sola RG, Puigdellivol-Sanchez A, Arriazu Navarro R, De Andres JA. [Structure of the arachnoid layer of the human spinal meninges: a barrier that regulates dural sac permeability]. Rev Espan Anestesiol Reanimacion. 2010;57:486-92.

16. Reina MA, Maches F, López A, De Andres JA. The ultrastructure of the spinal arachnoid in humans and its impact on spinal anesthesia, cauda equina syndrome, and transient neurological syndrome. Techni Regional Anesth Pain Manage. 2008;12:153-60.

17. Ghogawala Z, Dziura J, Butler WE, et al. Laminectomy plus fusion versus laminectomy alone for lumbar spondylolisthesis. N Engl J Med. 2016;374:1424-34.

18. Forsth P, Olafsson G, Carlsson T, et al. A randomized, controlled trial of fusion surgery for lumbar spinal stenosis. N Engl J Med. 2016;374:1413-23.

19. Kratzsch T, Stienen MN, Reck T, Hildebrandt G, Hoederath P. Catheter-tip granulomas associated with intrathecal drug delivery -a two-center experience identifying 13 cases. Pain Physician. 2015;18:E831-40. 